\title{
Decadal windstorm activity in the North Atlantic-European sector and its relationship to the meridional overturning circulation in an ensemble of simulations with a coupled climate model
}

\author{
Katrin M. Nissen • Uwe Ulbrich • Gregor C. Leckebusch • \\ Ivan Kuhnel
}

Received: 25 April 2013/Accepted: 12 October 2013/Published online: 5 November 2013

(C) The Author(s) 2013. This article is published with open access at Springerlink.com

\begin{abstract}
The relationship between decadal variations in the North Atlantic meridional overturning circulation (MOC) and North Atlantic/Western European windstorm activity during the extended winter season is studied. According to an ensemble of three 240-year long simulations performed with the ECHAM5-MPIOM model, periods of high decadal windstorm activity frequently occur in the years following a phase of weak MOC (i.e. when the MOC starts to recover). These periods are characterised by a distinctive pattern in the mixed layer ocean heat content (OHC). A positive anomaly is located in the region $45^{\circ} \mathrm{N}-$ $52^{\circ} \mathrm{N} / 35^{\circ} \mathrm{W}-16^{\circ} \mathrm{W}$ (west of France). Negative anomalies are located to the North and South. The signal can be detected both in the heat content of the oceanic mixed layer and in the sea surface temperatures. Its structure is consistent with anomalously enhanced baroclinic instability in the region with the strong negative $\mathrm{OHC}$ gradient $\left(30^{\circ} \mathrm{W}-\right.$ $10^{\circ} \mathrm{W} / 45^{\circ} \mathrm{N}-60^{\circ} \mathrm{N}$ ), which eventually produces a higher probability of windstorms.
\end{abstract}

Keywords Decadal variability · Windstorms · MOC

K. M. Nissen $(\bowtie) \cdot$ U. Ulbrich

Institute for Meteorology, Freie Universität Berlin, Carl-Heinrich-Becker-Weg 6-10, 12165 Berlin, Germany

e-mail: katrin.nissen@met.fu-berlin.de

G. C. Leckebusch

School of Geography, Earth and Environmental Sciences, University of Birmingham, Edgbaston,

Birmingham B15 2TT, UK

I. Kuhnel

Model Development Group, EQECAT, 75009 Paris, France

\section{Introduction}

Skillful decadal climate forecasts for the North Atlantic and Europe are of high scientific interest, but the research on this subject is still at an early stage. The North Atlantic is known to exhibit decadal to multidecadal variability. Moreover, the North Atlantic has been identified as one of the regions where decadal predictability is likely to exist (Latif et al. 2006, and references therein).

Windstorm activity in the North Atlantic/Western European region, being one of the major hazards for this region, is exhibiting pronounced decadal variability (e.g., Donat et al. 2011; Wang et al. 2009). Decades with especially high windstorm activity are associated with enormous monetary losses as for example seen during the 1990's. It is of interest to investigate, if and how the decadal variations in windstorm activity over the North Atlantic and European sector can be related to low-frequency variations in the North Atlantic.

Previous studies have already investigated the influence of the ocean on the mean state of the atmosphere, for example on the storm track (i.e. bandpass-filtered variance in the $500 \mathrm{hPa}$ height field) and on the North Atlantic Oscillation (NAO). It is known that windstorms, NAO and the storm track are related. The position of the storm track is influenced by the phase of the NAO, with a positive NAO being associated with a more northerly storm track (e.g. Hurrell and van Loon 1997), a higher number of extreme cyclones (e.g. Pinto et al. 2009) as well as a higher number of windstorms affecting northern Europe (e.g. Donat et al. 2010a). The relationship between the NAO and European windstorms is, however, not linear. Most storm days are associated with a moderately positive phase of the NAO (Donat et al. 2010a). The NAO typically peaks two days prior to the time of maximum destructiveness and 
exhibits an anomalous shift of its low-pressure centre towards the east (Hanley and Caballero 2012).

With regard to the ocean, previous studies have used a variety of parameters to describe the ocean's state. Some studies are based on sea surface temperatures (SSTs) and their anomalies in the North Atlantic or the tropics (e.g. ENSO). Other studies focus on ocean dynamics and consider the state of the thermohaline or Atlantic meridional overturning circulation (MOC), which is commonly determined by zonally integrating the Atlantic stream function (e.g. Pohlmann et al. 2013). Some studies also investigate the influence of the North Atlantic gyre circulation, which seems to play a less important role for the atmospheric winter variability than the MOC (Gastineau et al. 2013).

A relationship between SSTs in the North Atlantic Ocean and the storm track has been established in several studies analysing idealised model simulations (Brayshaw et al. 2008, 2011; Wilson et al. 2009; Nakamura et al. 2008). The authors agree that the location and strength of the storm track is influenced by SST anomalies. Introducing a meridional SST gradient in the western North Atlantic region associated with the Gulf Stream enhances the storm track downstream.

The response of the atmosphere to Atlantic MOC variability has been analysed by Gastineau and Frankignoul (2012) using six global climate models. An intense MOC is followed by a weak NAO and a southward shift of the storm track consistent with a horseshoe shaped anomaly in the SSTs. The lag between the MOC and the atmospheric response varies between 4 and 9 years depending on the model. Woollings et al. (2012) relate simulated changes of the storm track under climate change conditions to the weakening of the MOC anticipated in response to increasing greenhouse-gas concentrations, using 22 coupled climate models. A complete shutdown of the MOC in the Met Office Unified Model (HadCM3) results in an intensification and eastward extension of the North Atlantic storm track (Brayshaw et al. 2009).

Even though most investigations see an effect of the ocean variability on the atmosphere, there is still no consensus regarding the significance of this effect. For the seasonal to interannual time scale observations suggest that the influence of the extratropical atmosphere on the ocean is higher than the influence of the ocean on the atmosphere (e.g. Cayan 1992; Kushnir et al. 2006; Kwon et al. 2010). Still, some influence of the ocean on the atmosphere can also be detected (Frankignoul and Kestenare 2005; Renggli et al. 2011).

On the decadal to multidecadal time scale the atmospheric response to the ocean variability seems to be more significant than for the shorter time scales due to the ocean's thermal inertia and relative slow dynamics (Bjerknes 1964; Delworth et al. 1993; Latif 1998). Several authors have studied the link between North Atlantic ocean variability and the NAO on the decadal time scale and found that the state of the NAO can be reconstructed/ predicted to some extent from North Atlantic SSTs (e.g., Rodwell et al. 1999; Sutton and Hodson 2003; Eden et al. 2002). Model results suggest that the decadal variations at the ocean surface can be caused by low frequency variations in the ocean circulation, e.g. the MOC (Gastineau et al. 2013). In addition, the seasonal cycle of mixed layer depth can induce winter to winter memory of SST anomalies (Deser et al. 2010, and references therein).

Even for the low-frequency time scale there is evidence for atmospheric variability to influence the ocean. Latif et al. (2004) found that multidecadal variations in the MOC lag multidecadal changes in the NAO by about a decade. In the MPIOM ocean model, which is used for this study, internally generated (30-year variability) and coupled ocean-atmosphere variations (60-year variability) in the MOC co-exist (Zhu and Jungclaus 2008).

In this paper the possible influence of decadal variations in the ocean circulation on windstorm activity in the North Atlantic-European sector is investigated. In contrast to previous studies described in the literature we focus on extremes (i.e. windstorms) rather than the mean state (e.g. storm track or NAO). Studies on the relation of extreme and moderate cyclones indicate that there is a difference in the spatial distribution (Pinto et al. 2009).

A potential chain of mechanisms producing decadal windstorm variability is suggested and assessed: Decadal variations in the Atlantic MOC affect the ocean heat transport and lead to anomalies in the ocean heat content (OHC) and the SSTs. Characteristic anomaly patterns, which are associated with the MOC variations have the potential to enhance atmospheric baroclinicity. This creates favourable conditions for the development of extreme cyclones and can increase the decadal windstorm activity. In accordance to most other studies investigating reasons for decadal variability this investigation is based on model simulations as there is a lack of adequate long term observational time series.

\section{Data and method}

The investigation is based on three 240-year long simulations with the ECHAM5-MPIOM model (e.g., Roeckner et al. 2006; Jungclaus et al. 2006). The simulations cover the period 1860-2100 and have been forced with observed greenhouse gas concentrations between 1860 and 2000 and with SRES A1B scenario concentrations 
afterwards. The choice of the model was motivated by an intensive comparison between models and observations performed within the ENSEMBLES project (http://www. ensembles-eu.org). In particular, it was shown that both winter storm activity simulated by this model for present day greenhouse gas forcing, and its change under increasing greenhouse gas concentrations are close to the multi model ensemble mean of the 7 models investigated in the project (Ulbrich et al. 2008; Donat et al. 2010b). Moreover, the ECHAM5-MPIOM model simulates the most important source for decadal variations in the Atlantic, the MOC, especially well (Collins et al. 2006).

Windstorms are identified using a method developed by Leckebusch et al. (2008). The $10 \mathrm{~m}$ wind field is scanned for grid boxes in which the wind speed exceeds the local 98th percentile. The use of this percentile has been demonstrated to be useful in the context of reproducing observed losses from windstorms (e.g., Klawa and Ulbrich 2003). Adjoining grid boxes with extreme wind speeds form a cluster. The clusters are then tracked in time by using a nearest neighbour approach. Only the wind tracks, which last at least $18 \mathrm{~h}$ (4 time steps archived from the model runs) and cover an area of at least $217,000 \mathrm{~km}^{2}$ per time step (corresponding to 5 grid boxes at the equator) are kept. In the context of this study, North Atlantic windstorm activity is defined as the number of extreme wind tracks per extended winter season (October-March) crossing the region $45^{\circ} \mathrm{W}-20^{\circ} \mathrm{E} / 45^{\circ} \mathrm{N}-70^{\circ} \mathrm{N}$ (see rectangle in Fig. 9).

In order to analyse variations in the Atlantic MOC, the annual mean of the meridional overturning stream function is determined and a MOC index constructed using the maximum values in the North Atlantic (below $500 \mathrm{~m}$ and north of $28^{\circ} \mathrm{N}$ ) as suggested by Yoshimori et al. (2009).

The annual mean $\mathrm{OHC}$ is calculated for the upper $300 \mathrm{~m}$ in $1^{\circ} x 1^{\circ}$ grid boxes from the potential temperatures simulated by the MPIOM model:

$O H C=\iiint \rho_{0} c_{p}\left(\Theta-\Theta_{r e f}\right) \mathrm{d} x \mathrm{~d} y \mathrm{~d} z$,

with $\Theta=$ potential temperature, $\Theta_{\text {ref }}=273.15 K, c_{p}=$ $4000 \mathrm{~J} / \mathrm{kg} / \mathrm{K}$ the heat capacity of ocean water and $\rho_{0}=1,025 \mathrm{~kg} / \mathrm{m}^{3}$ the density of ocean water at the surface.

The term "decadal" commonly refers to the 10-30 year time scale (Meehl et al. 2009). In this paper we separate variability on the decadal time scale by applying a 10-35 year band pass filter (Doblas-Reyes and Déqué 1997) to the time series of storm activity, MOC and $\mathrm{OHC}$. This also removes long-term trends caused by the increasing greenhouse gas concentrations in the climate change simulations. Unless stated otherwise the following results are all based on these filtered time series.

\section{Relationship between windstorm activity and the ocean circulation}

\subsection{The MOC and windstorm activity}

Wavelet analysis (Torrance and Compo 1998) applied to the unfiltered but normalised and detrended time series, confirms that the MOC and the windstorm activity time series include variability in the the 10-35 year period range, which differs statistically significant from white noise (not shown). In particular, all runs exhibit periods with significant variability around 30 years and around 60 years, in line with the results of Zhu and Jungclaus (2008), who also reported MOC variability with periods around 30 and 60 years in the MPIOM model. The simulations analysed here additionally include variability with shorter periods (around 10 and 20 years), which reaches statistically significant levels in 2 out of the 3 simulations.

Cross spectral analysis between the two unfiltered time series shows coherence on the decadal time scale for all runs with values up to 0.7 , which is statistically significant on the $95 \%$ level for 2 out of the 3 simulations (not shown).

Relating the decadal (band-pass filtered) windstorm activity to the state of the MOC in the North Atlantic region reveals that periods with high decadal windstorm activity are identified with higher-than-average frequency during years in which the ten-year rate of change of the MOC is positive (Fig. 1). A positive rate of change indicates a transition of the MOC from a weak towards a strong phase. Both Pearson's chi-squared test (e.g. Plackett 1983)

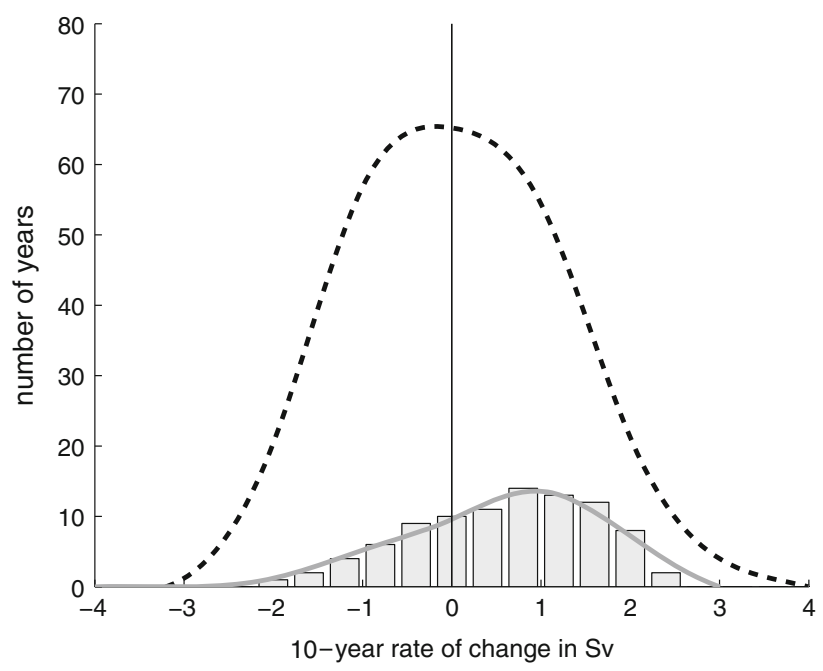

Fig. 1 Frequency distribution of MOC phase including all 3 ensemble simulations. Solid line: Number of years with windstorm frequency $>1 \sigma$ counted in classes depending on the MOC rate of change per 10 years. Broken line: Total number of years within each MOC class. Counted in intervals of $0.4 \mathrm{~Sv} / 10$ years. The curves are smoothed. The analysis is based on bandpass filtered time series 

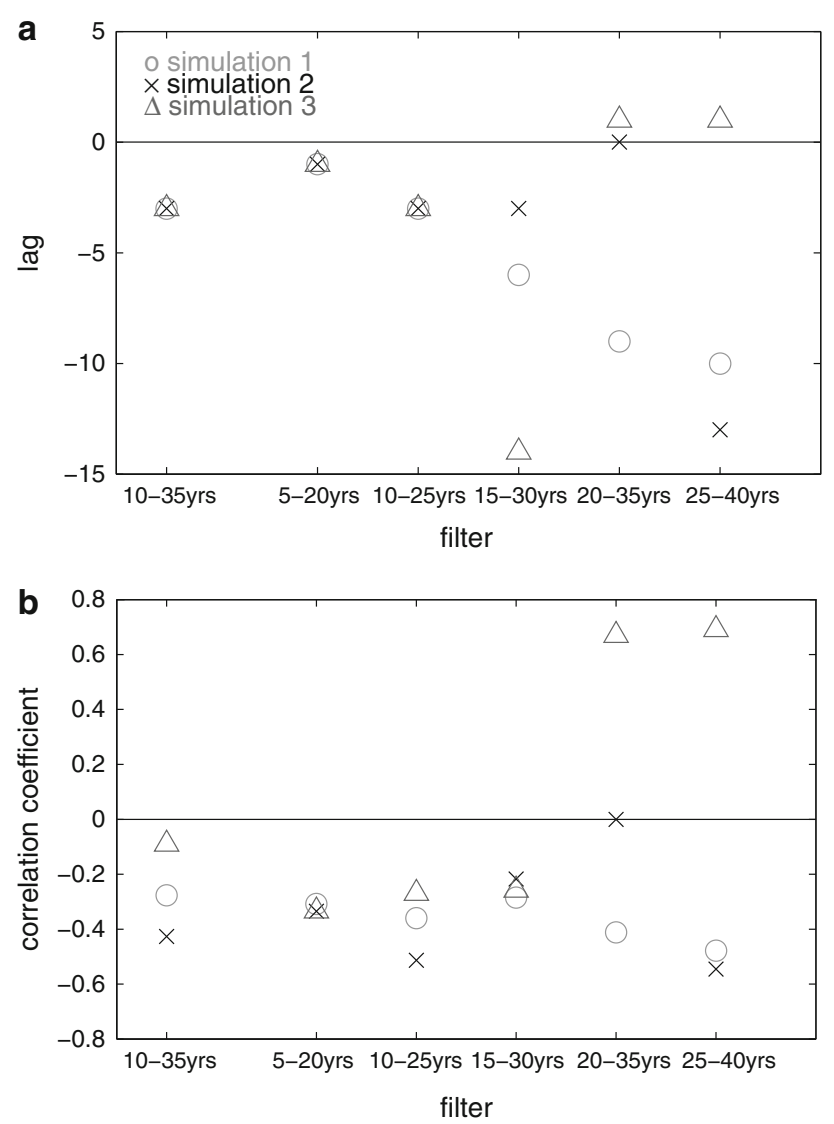

Fig. 2 Influence of bandpass filter range on the correlation between MOC and windstorm activity. a Lag between MOC time series and windstorm time series. Negative lags indicate that strong windstorm activity follows after a MOC minimum. Positive lags indicated that strong windstorm activity follows after a MOC maximum. b Correlation coefficient at the lag shown in panel (a)

and Student's t-test suggest that the cumulation of periods with high windstorm activity at this transitional MOC phase is statistically significant on the $99 \%$ level.

For the analysed period range of 10-35 years lag correlation between the MOC and windstorm timeseries suggests a coherent phase relationship between the two time series in all three runs with the the strongest storm activity following 3 years after the occurrence of a MOC minimum (Fig. 2). Varying the period range that passes the bandpass filter shows that the three simulations exhibit coherent behaviour for period ranges between 5 and 30 years: Maxima in windstorm activity tend to occur between a minimum and a maximum in the MOC. At periods above 30 years, however, this phase relationship disappears (Fig. 2).

\subsection{OHC and SSTs}

Variations in the MOC can alter the heat transport in the ocean. Resulting anomalies in the ocean heat content may influence the atmosphere via the SSTs. The following subsection investigates, whether high decadal windstorm activity is associated with characteristic anomalies in the upper level OHC and SSTs in the North Atlantic region.

Comparing periods with high and low decadal windstorm frequency (greater/lower than 1 standard deviation with respect to the local average using the band-pass filtered time series), a distinct signal of anomalous $\mathrm{OHC}$ in the upper $300 \mathrm{~m}$ of the North Atlantic Ocean is found (Fig. 3). Years with high storm activity are associated with a positive OHC anomaly along the path of the North Atlantic Current (NAC) with especially high anomalies in the region around $48^{\circ} \mathrm{N} 25^{\circ} \mathrm{W}$. Negative anomalies exist north and south of this area. The signal is present in all three individual simulations and the ensemble mean. Statistical significance of the anomalies is above the $90 \%$ level and reaches the $99 \%$ level at individual grid points according to a local t-test. Correlating the decadal windstorm frequency time series with the $\mathrm{OHC}$ in the North Atlantic reveals the same areas with significant correlations between the two time series (not shown). The exact location and strength of the signal varies only slightly between the three runs.

To describe the variations of this anomaly in time an OHC Anomaly Index (OAI) can be constructed as follows:

$O A I=O H C_{\text {warm }}-0.5 \times\left(O H C_{\text {cold } 1}+O H C_{\text {cold } 2}\right)$,

using the central (warm and cold) areas indicated in Fig. 3. The regions have been optimised to fit the individual simulations as well as the ensemble mean (warm: $35^{\circ} \mathrm{W}-$ $16^{\circ} \mathrm{W} / 45^{\circ} \mathrm{N}-52^{\circ} \mathrm{N}, \quad$ cold $1: \quad 35^{\circ} \mathrm{W}-15^{\circ} \mathrm{W} / 53^{\circ} \mathrm{N}-60^{\circ} \mathrm{N}$, cold2: $35^{\circ} \mathrm{W}-18^{\circ} \mathrm{W} / 28^{\circ} \mathrm{N}-32^{\circ} \mathrm{N}$ ). The OAI is determined using these areas for all three simulations.

The correlation coefficient between the band pass filtered winter storm activity and OAI time series is between 0.33 and 0.54 in the 3 individual simulations (crosses in Fig. 4). Thus the decadal OHC anomaly can explain about $10-30 \%$ of the decadal storm variability. To ensure that the correlation between storm activity and $\mathrm{OHC}$ on the decadal time scale is not an artefact of the methodology (filtering), a test was conducted: The statistical significance of the correlation was determined by generating $3 \times 1,000$ surrogate windstorm activity time series. The surrogates share the power spectrum and the probability distribution with the original time series, only the Fourier-phase is randomised (Schreiber and Schmitz 2000). The random series were band pass filtered (range 10-35 years) and correlated with the filtered OAI time series. The box plots in Fig. 4 denote median (centre line), 25th and 75th percentile (edges of the box), as well as the 5th and 95th percentile (whiskers) of the 1,000 resulting correlation coefficients. The correlation between OAI and decadal winter storm activity is thus significant above the $95 \%$ 
Fig. 3 Composite of ocean heat content in the upper $300 \mathrm{~m}$.

Years with storm frequency $>1$ $\sigma$ minus years with windstorm frequency $<1 \sigma$. Only areas with differences significant above the $90 \%$ significance level are shaded. Unit J. The rectangles denote the definition of areas for the calculation of the Ocean heat content Anomaly Index (OAI)

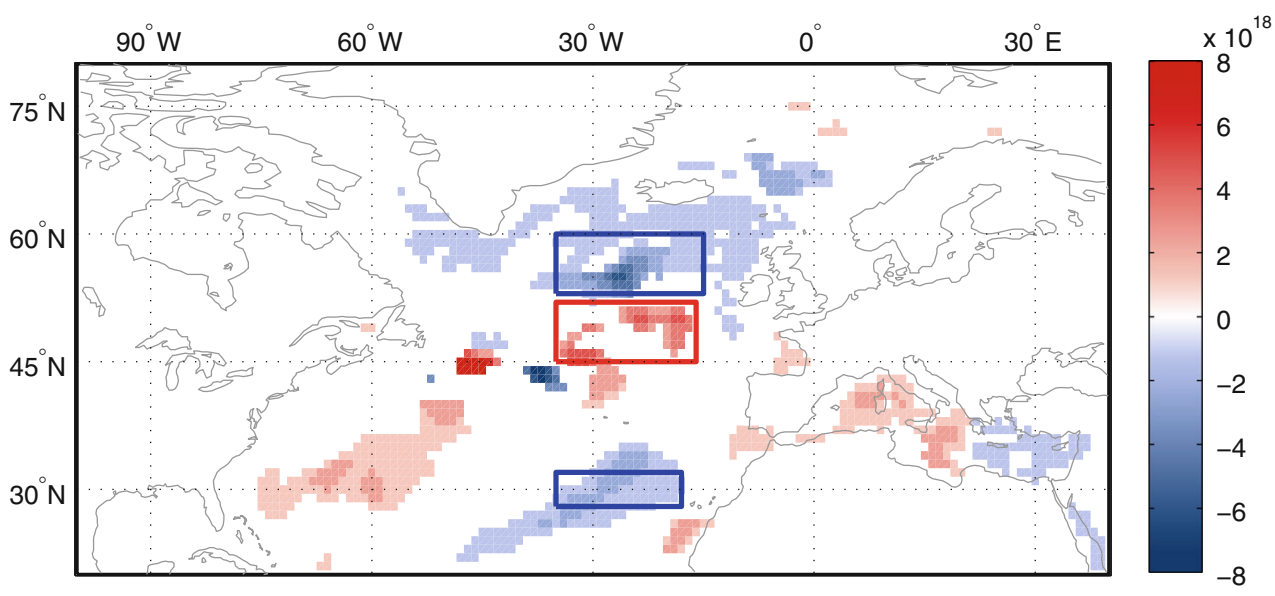

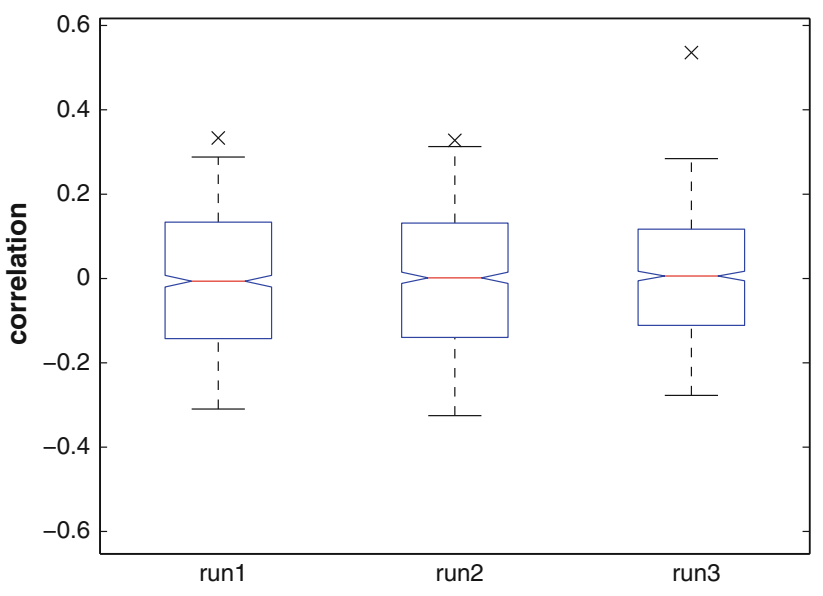

Fig. 4 Correlation between OAI and decadal North Atlantic storm activity (black crosses). For significance testing the correlations between OAI and 1,000 band pass filtered surrogate time series, which exhibit the same power spectrum and probability distribution as the windstorm time series, are determined (box plot). The whiskers span the range between the highest and lowest $5 \%$ of these correlation coefficients

level for all simulations and even above the $99 \%$ level for simulation 3. The results are consistent for all three simulations, suggesting a stable relationship between the decadal variation in the upper level ocean heat content of the North Atlantic and winter storm activity.

In order to further test the robustness of our results a number of sensitivity tests have been conducted. Using the $\mathrm{OHC}$ of the upper $500 \mathrm{~m}$ instead of the upper $300 \mathrm{~m}$ leads to approximately the same $\mathrm{OHC}$ anomaly pattern.

The correlation coefficients obtained using seasonal mean instead of annual mean $\mathrm{OHC}$ values have been determined for all seasons and were found to be almost identical to those using annual means. This is due to the fact that the $\mathrm{OHC}$ anomalies are already present in the months prior to the occurrence of the winter storms and indicates that the $\mathrm{OHC}$ anomalies are not solely a response to the atmospheric windstorm forcing.
During periods with high wind storm activity the anomalies detected in the upper level $\mathrm{OHC}$ are reflected in the band pass filtered annual mean sea surface temperatures. The composite features positive deviations from the long-term mean along the path of the NAC and negative anomalies towards the north and south (Fig. 5).

\subsection{The link between the MOC and $\mathrm{OHC}$}

It still remains to be investigated whether the detected anomalies in OHC are caused by variations in the MOC. We test the hypothesis of a connection between the $\mathrm{OHC}$ anomalies and the MOC using lag correlations. The correlations are determined between the OAI and the band pass filtered MOC index for the 3 simulations. The highest OAI values develop 1-3 years after the lowest MOC index (weak MOC), thus suggesting that the OAI is highest during the transition of the MOC from its negative to its positive phase (Fig. 6). The correlation coefficient reaches values between 0.2 and 0.6 , depending on the model simulation. According to a t-test the correlation between the MOC and the OAI indices is statistically significant above the $99 \%$ level at the times of the lowest MOC index for all individual simulations (not shown). The approximate phase agreement of the lag correlation curves for the 3 simulations also points towards a physical relationship between the $\mathrm{OHC}$ anomalies and the MOC.

Variability in the MOC of the ECHAM5-MPIOM model has been analysed by Zhu and Jungclaus (2008). They identified two distinct periods of approximately 60 years and of approximately 30 years. While the 60 year period was identified as an coupled atmosphere-ocean mode, the 30 year oscillation is an ocean internal mode as it also exists when the ocean model is forced using a climatological mean atmosphere. Moreover, Zhu and Jungclaus (2008) demonstrate that the years following the negative phase of the 30 year MOC mode are associated with an upper ocean temperature signal, very similar to the one 
Fig. 5 Composite of annual mean SSTs. Years with windstorm frequency $>1 \sigma$ minus years with windstorm frequency $<1 \sigma$. Unit: $\mathrm{K}$

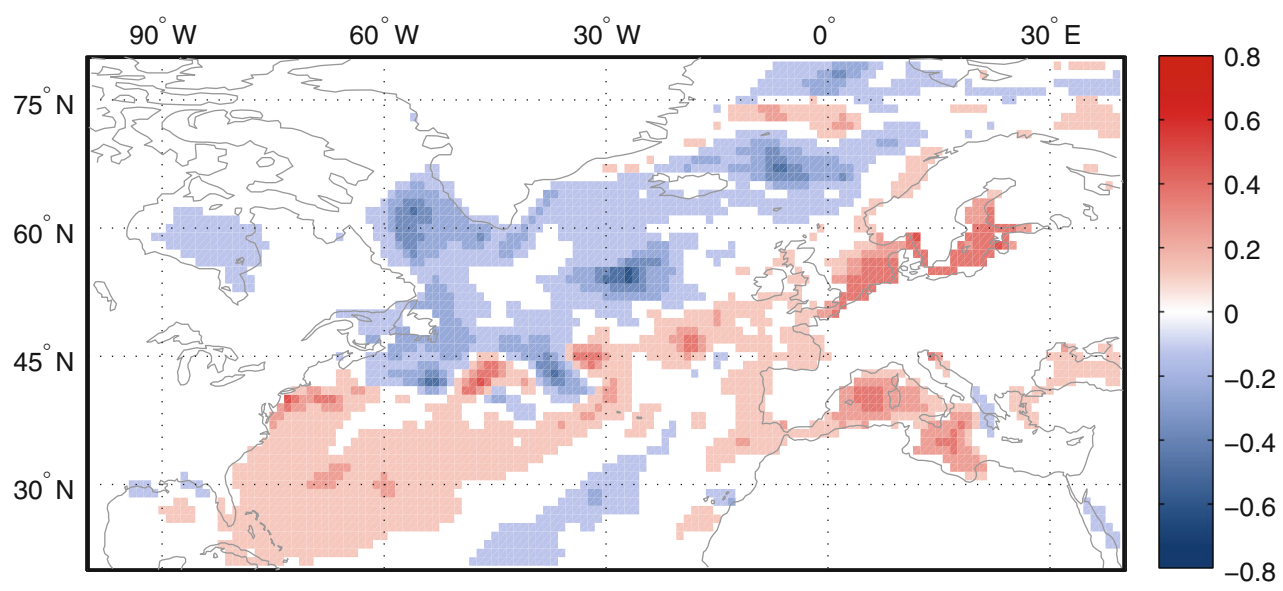

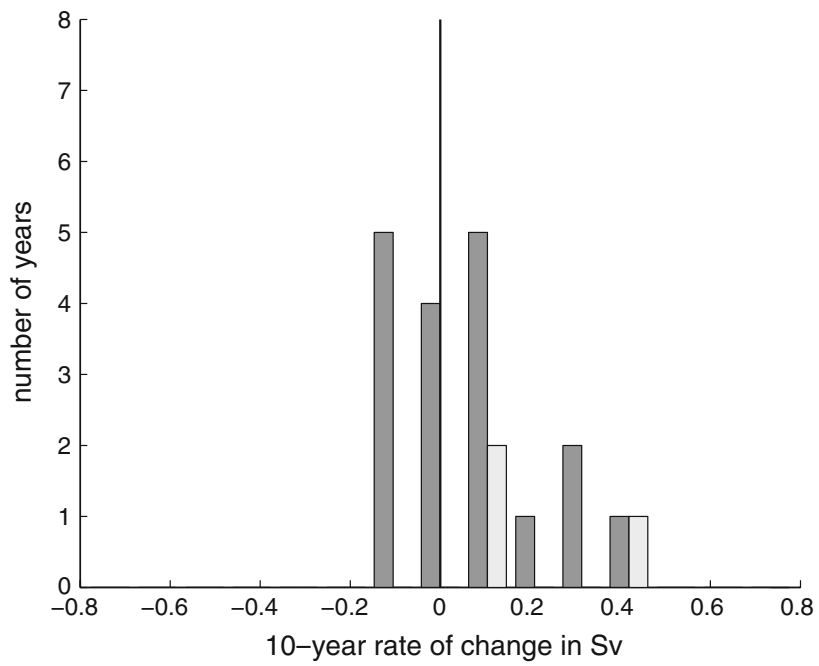

Fig. 7 Frequency distribution of MOC phase. Light bars: Number of years with windstorm frequency $>1 \sigma$ counted in classes depending on the MOC rate of change per 10 years. Dark bars: Total number of years within each MOC class. Counted in intervals of $0.1 \mathrm{~Sv} /$ 10 years. Analysis based on MOC estimate from 10 ocean reanalysis data sets and windstorm frequency determined from NCEP NCAR reanalysis. Both time series are bandpass filtered

frequency in the region $45^{\circ} \mathrm{W}-20^{\circ} \mathrm{E} / 45^{\circ} \mathrm{N}-70^{\circ} \mathrm{N}$ is determined using the method described in Sect. 2 using NCEP reanalysis data (Kalnay et al. 1996). Band pass filtering leaves 2 distinct periods with high decadal wind storm activity with maxima in 1973 and in 1991. A minor maximum occurs in 1982.

Time series of the Atlantic MOC are only available from ocean reanalysis. Pohlmann et al. (2013) compares the Atlantic MOC in 10 recent reanalysis data sets and reports a common signal of variability at $45^{\circ} \mathrm{N}$. Comparison of the band pass filtered time series of observed windstorm frequency with the band pass filtered ensemble mean of the available MOC time series suggests coincidence of the maxima in wind activity with periods during which the Atlantic MOC recovers from a weak phase (Fig. 7). This 
Fig. 8 Composite of observed annual mean SSTs. Years with windstorm frequency $>1 \sigma$ minus years with windstorm frequency $<1 \sigma$. Unit: K. The analysis is based on NOAA extended reconstructed SSTs and windstorm frequency determined from NCEP NCAR reanalysis. Both time series are bandpass filtered

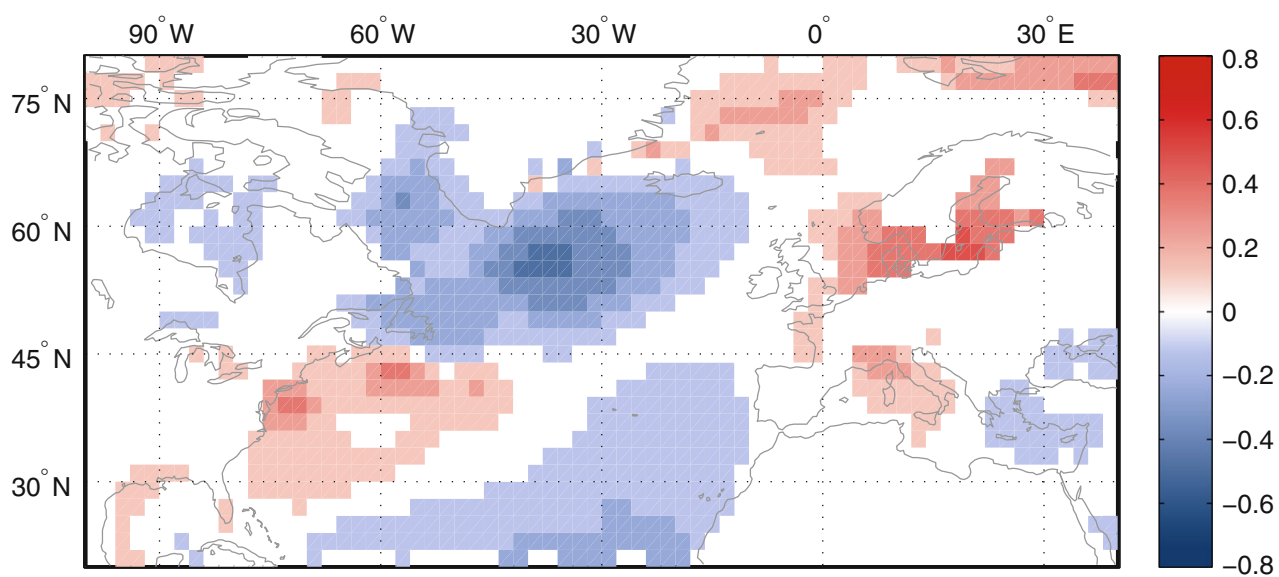

supports the model results, which show the same phase relationship between decadal wind storm frequency in the North Atlantic region and the MOC.

Observed SST anomalies (Smith et al. 2007) are analysed using NOAA ERSST V3 data provided by the NOAA/OAR/ESRL PSD, Boulder, CO, USA, from their Web site at http://www.esrl.noaa.gov/psd/. Comparing observed periods of high decadal windstorm activity with periods of low activity reveals a SST pattern similar to the one found in the model (Figs. 8, 5). Negative anomalies are located north and south of the NAC. Positive anomalies in the NAC region span from the Gulf of Mexico to $45^{\circ} \mathrm{W}$. Further east the SST differences in the NAC region disappear, which is in contrast to the model results that show positive anomalies along the entire NAC. Nevertheless, the resulting meridional SST gradients are similar in the model and the observations.

\section{Mechanism translating ocean temperature anomalies into storms}

The SST anomalies west of the British Isles, developing during the transition of the MOC from a weak to a strong phase, are associated with an increased meridional temperature gradient. This is consistent with an increase of atmospheric baroclinic instability in this region due to heat transfer anomalies. The heat transfer over the region is mostly directed from the ocean into the atmosphere and most pronounced during the cold season, when the temperature contrast between the ocean and the atmosphere is highest (Liu et al. 1979; Yu and Weller 2007).

Baroclinicity is known to be a factor for cyclone growth. On the daily and seasonal time scale enhanced cyclone and enhanced storm activity in the North Atlantic was found to be associated with enhanced baroclinicity (Ulbrich et al. 2001; Pinto et al. 2009; Renggli et al. 2011). We find evidence that this relationship also holds on the decadal time scale (Fig. 9). As a measure of baroclinic instability we use Eady growth rates (e.g., Hoskins and Valdes 1990), which have been computed at individual locations from daily mean data and averaged for each extended winter season in the lower troposphere (between the 700-850 hPa levels). Again, the band pass filter for periods between 10 and 35 years is applied. Comparing periods with high and low decadal windstorm activity (storms crossing the area denoted by the black rectangle in Fig. 9), a positive band of enhanced Eady growth rates is found for the former along the main North Atlantic cyclone track. According to a Student's t-test the anomalies are highly significant on the $99 \%$ level. The highest values occur at the North American coast (Fig. 9).

We investigated further, in how far the detected $\mathrm{OHC}$ anomalies are associated with high Eady growth rates and thus favourable growth conditions for cyclones and associated extreme wind tracks. Composites of the Eady growth rate with respect to the ocean state are calculated using the ensemble's 19 periods with strong OAI (OAI $>1 \sigma)$ and the 19 periods with low OAI values $(\mathrm{OAI}<1 \sigma)$ from the band pass filtered time series. The highest anomalies can be found over the North East Atlantic Ocean (Fig. 10). Compared to Fig. 9 the anomalies are weaker (please note the different scales), but the statistical significance level at the centre of the anomalies also exceeds the $99 \%$ level. The positive anomalies in the Eady growth rates are spatially and temporally consistent with the negative $\mathrm{OHC}$ gradient between $45^{\circ} \mathrm{N}$ and $60^{\circ} \mathrm{N}$ (Fig. 3), which is also present in the SSTs (Fig. 5). Apparently, the decadal OHC anomalies induce equator-ward warming and pole-wards cooling in the atmosphere in the same region, enhancing baroclinicity. Thus, during decades with high storm activity variations in the baroclinicity support the genesis and growth of cyclones along the entire region of the main North Atlantic cyclone path. One part of this signal - the decadal baroclinicity variations in the North Eastern Atlantic (upstream and close to the European continent)- 
Fig. 9 Composite of band pass filtered Eady growth rate between 850 and $700 \mathrm{hPa}$ during the winter season. Difference between periods with decadal windstorm activity above/below 1 standard deviation. Only areas with differences significant above the $90 \%$ significance level are shaded. Unit day ${ }^{-1}$
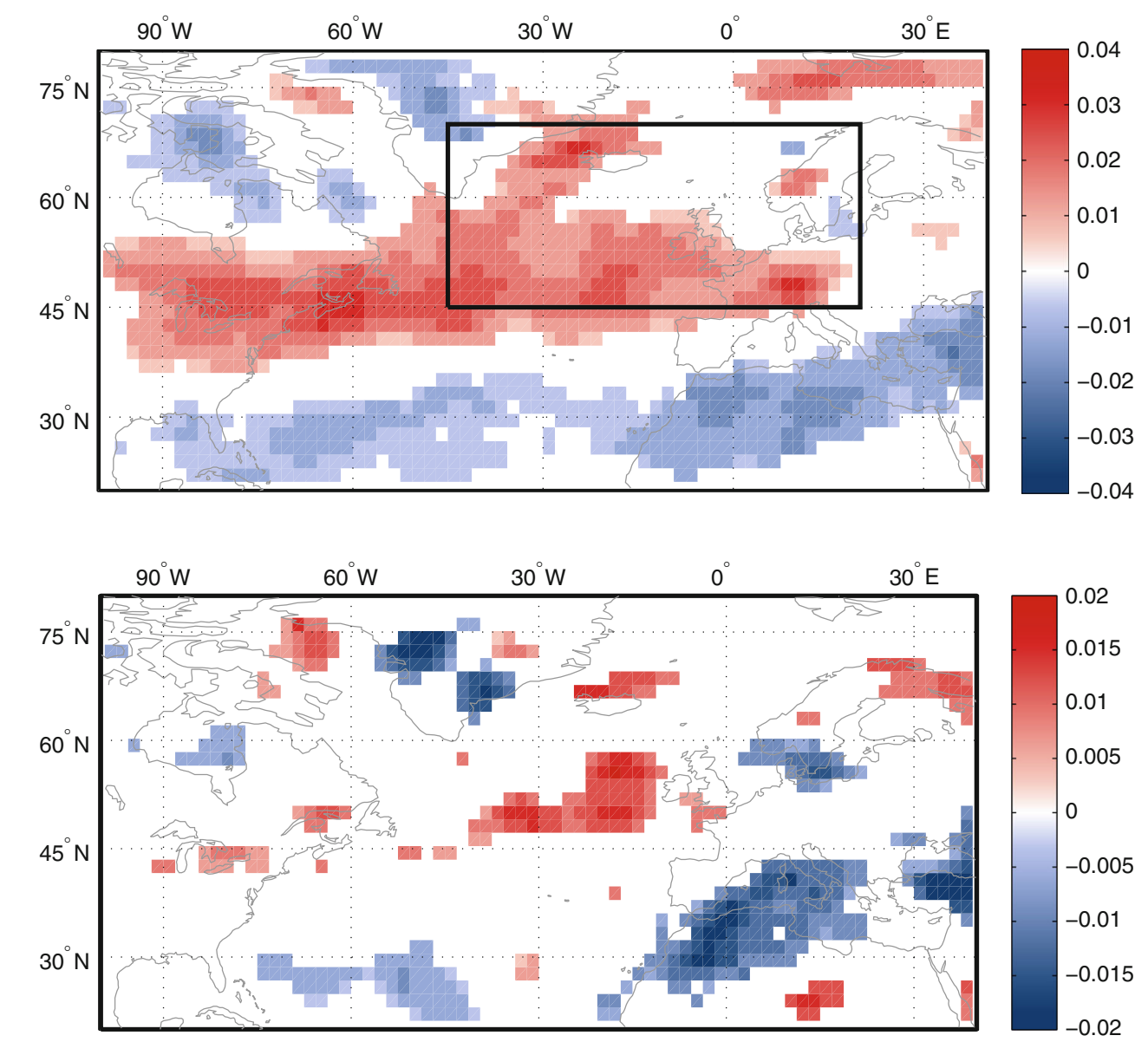

Fig. 10 Composite of band pass filtered Eady growth rate during the winter season. Difference between periods with OAI above/below 1 standard deviation. Only areas with differences significant above the $90 \%$ significance level are shaded. Unit day ${ }^{-1}$ can thus be related to local OHC anomalies associated with variations in the MOC.

\section{Conclusions}

A statistically significant relationship has been detected between decadal variations in the MOC and windstorm frequency over the North Atlantic/European region using an ensemble of coupled climate simulations with the ECHAM5-MPIOM model. A sequence of physical mechanisms to link the MOC with windstorm activity is suggested by the data (Fig. 11): Variations in the MOC cause variations in the ocean heat transport and induce a specific pattern of anomalies in the mixed layer $\mathrm{OHC}$. The $\mathrm{OHC}$ anomalies are reflected in the SSTs. The SST anomalies lead to enhanced Eady growth rates west of the British Isles and thus favourable conditions for cyclone growth in the vicinity. This again increases the potential for the development of windstorms. The existence of a relationship between enhanced North Atlantic SST gradients caused by MOC changes and a strengthening and eastward extension of the Atlantic storm track has also been demonstrated by Woollings et al. (2012). The authors studied long term trends (rather than decadal variability) in a multi-model ensemble of climate change scenario simulations. While the long term trend in the SST gradient is likely to be caused by a weakening of the MOC, our results suggest that the decadal variability in the SST gradient is related to phase shifts in the MOC. This is also supported by Gastineau and Frankignoul (2012) who were able to establish a link between MOC and NAO variability via changes in the heat flux and Eady growth rates using 6 coupled climate models.

It is known that variations in the strength of the MOC are caused by changes in the density structure of the North Atlantic, which are due to fluctuations in salinity and temperature. For the decadal variations in the MPIOM model Zhu and Jungclaus (2008) find that the strongest contribution comes from temperature fluctuations. They also show that a weak North-South density gradient is followed by a weak MOC with a time lag of about 2 years and a weak North Atlantic Current with a time lag of about 3 years. At the time of the MOC minimum warm near surface temperature anomalies appear east of Newfoundland and are advected eastward when the MOC recovers. Consistent with these results, the mixed layer $\mathrm{OHC}$ anomalies associated with enhanced decadal wind activity, 


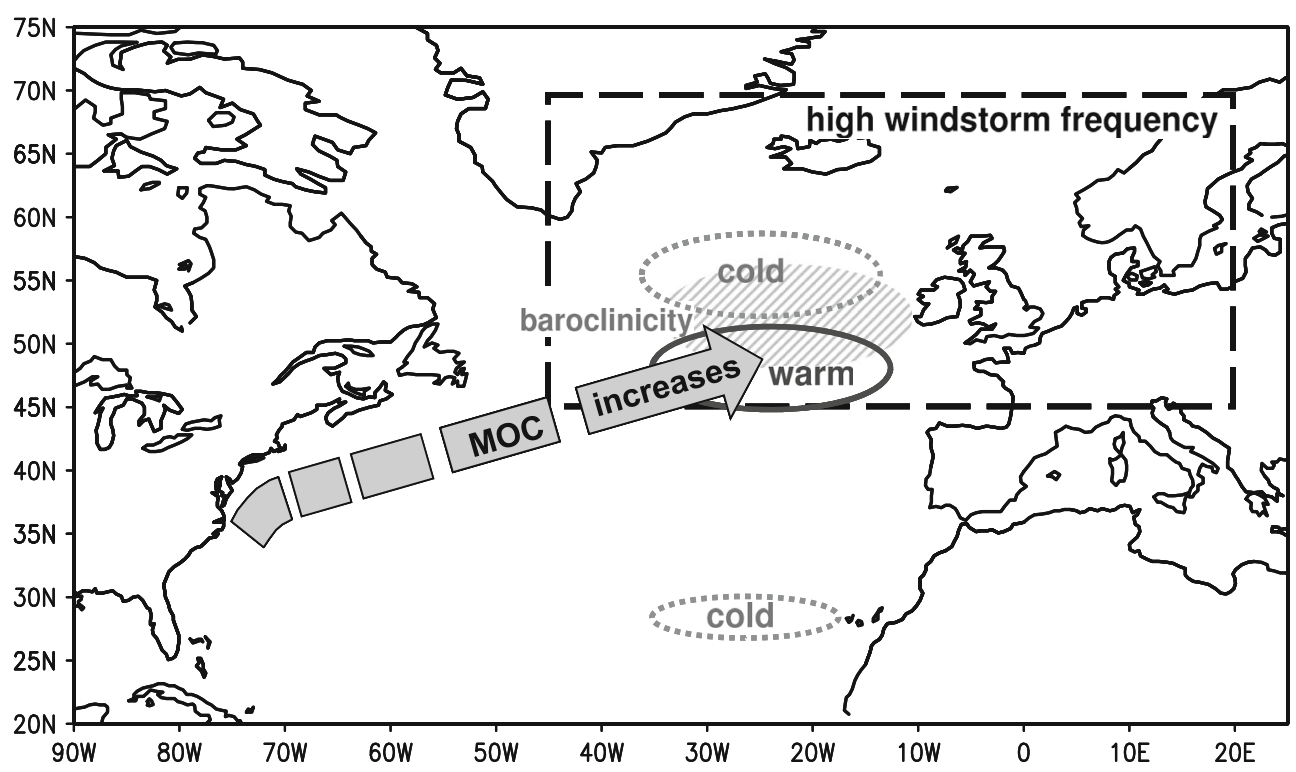

Fig. 11 Schematic presentation of the link between MOC, OHC, SSTs and Eady growth rates on the decadal time scale. The graphic depicts the situation 1-3 years after a decadal minimum in MOC strength. "warm" and "cold" denote areas with positive and negative

we find in our study, develop 1-3 years after the slowest period of the MOC and resemble the near surface temperature anomalies shown by Zhu and Jungclaus (2008).

Without additional (idealised) model simulations it is not possible to ultimately determine if or to which extent the ocean signals we detect in our study are caused by atmospheric forcing (i.e. the high wind speeds associated with the windstorms). A number of factors suggest, however, that ocean variability is the dominant cause for the signals:

1. The SST and OHC anomalies are already present in the months before the winter storms occur (see Sect. 3.2)

2. The study by Zhu and Jungclaus (2008) suggest that MOC variations with an approx. period of 30 years, which are included in the 10-35 year period range we have analysed in this study, are an ocean internal mode of the ECHAM5-MPIOM.

An index time series of the decadal $\mathrm{OHC}$ variations explains about $10-30 \%$ of the decadal storm variability in the North East Atlantic. This number is modest compared to the $52 \%$ of variability explained in the United State's multidecadal drought frequency by the combined influence of the Atlantic Multidecadal and Pacific Decadal Oscillation (McCabe et al. 2004), but still useful to better understand the observed decadal windstorm variability. As decadal variations in the MOC are believed to be potentially predictable (Pohlmann et al. 2013; Matei et al. 2012; Collins et al. 2006; Griffies and Bryan 1997), our modelbased results suggest that the decadal variations of North mixed layer OHC and SST anomalies. Positive anomalies of Eady growth rates (high baroclinicity) are present in the hatched area. High windstorm frequency is detected in the area denoted by the dashed rectangle

Atlantic storm activity may also be to some extent predictable.

Observations seem to support the results of this study, but the available observational time series are too short for robust conclusions. Further support of the results may come in the future, from the analysis of simulations of other coupled ocean atmosphere climate models.

Acknowledgments We are greatful for funding of this work by EQECAT, Paris and by the Federal Ministry of Education and Research in Germany (BMBF) through the research programme MiKlip (FKZ: 01LP1104A). Additional funding has been received from the People Programme (Marie Curie Actions) of the European Union's Seventh Framework Programme (FP7/2007-2013) under REA Grant agreement No. PCIG11-GA-2012-322208. We thank Dominik Renggli, Tim Kruschke and Henning Rust for valuable discussions and technical support. We would also like to thank the two anonymous reviewers for their comments, which helped to improve the manuscript.

Open Access This article is distributed under the terms of the Creative Commons Attribution License which permits any use, distribution, and reproduction in any medium, provided the original author(s) and the source are credited.

\section{References}

Bjerknes J (1964) Atlantic air-sea interaction. In: Landsberg HE, Van Mieghem J (eds) Advances in Geophysics, vol 10. Academic Press, New York, pp 1-82

Brayshaw DJ, Hoskins B, Blackburn M (2008) The storm-track response to idealized SST perturbations in an aquaplanet GCM. J Atmos Sci 65:2842-2860. doi:10.1175/2008JAS2657.1 
Brayshaw DJ, Woollings T, Vellinga M (2009) Tropical and extratropical responses of the North Atlantic atmospheric circulation to a sustained weakening of the MOC. J Clim 22:3146-3155. doi:10.1175/2008JCLI2594.1

Brayshaw DJ, Hoskins B, Blackburn M (2011) The basic ingredients of the North Atlantic storm track. Part II: sea surface temperatures. J Atmos Sci 68:1784-1805. doi:10.1175/2011JAS3674.1

Cayan DR (1992) Latent and sensible heat-flux anomalies over the northern oceans-driving the sea-surface temperature. J Phys Oceanogr 22:859-881. doi:10.1175/1520-0485(1992)022<0859: LASHFA $>2.0 . \mathrm{CO} ; 2$

Collins M, Botzet M, Carril AF, Drange H, Jouzeau A, Latif M, Masina S, Otteraa OH, Pohlmann H, Sortenberg A, Sutton R, Terray L (2006) Interannual to decadal climate predictability in the North Atlantic: a multimodel-ensemble study. J Clim 19:1195-1203

Delworth T, Manabe S, Stouffer RJ (1993) Interdecadal variations of the thermohaline circulation in a coupled ocean-atmosphere model. J Clim 11:1993-201. doi:10.1175/1520-0442(1993) 006<1993:IVOTTC $>2.0 . \mathrm{CO} ; 2$

Deser C, Alexander MA, Xie SP, Phillips A (2010) Sea surface temperature variability: patterns and mechanisms. Annu Rev Mar Sci 2:114-143

Doblas-Reyes FJ, Déqué M (1997) A flexible bandpass filter design procedure applied to midlatitude intraseasonal variability. Mon Weather Rev 126:3326-3335

Donat MG, Leckebusch GC, Pinto JG, Ulbrich U (2010a) Examination of wind storms over Central Europe with respect to circulation weather types and NAO phases. Int J Climatol 30:1289-1300. doi:10.1002/joc. 1982

Donat MG, Leckebusch GC, Wild S, Ulbrich U (2010b) Benefits and limitations of regional multi-model ensembles for storm loss estimations. Clim Res 44:211-225. doi:10.3354/cr00891

Donat MG, Renggli D, Wild S, Alexander LV, Leckebusch GC, Ulbrich U (2011) Reanalysis suggests long-term upward trends in European storminess since 1871. Geophys Res Lett 38:L14703. doi:10.1029/2011GL047995

Eden C, Greatbatch RJ, Lu J (2002) Prospects for decadal prediction of the North Atlantic Oscillation (NAO). Geophys Res Lett 29:1466. doi:10.1029/2001GL014069

Frankignoul C, Kestenare E (2005) Observed Atlantic SST anomaly impact on the NAO: An update. J Clim18:4089-4094. doi:10. 1175/JCLI3523.1

Gastineau G, Frankignoul C (2012) Cold-season atmospheric response to the natural variability of the Atlantic meridional overturning circulation. Clim Dynam 39:37-57. doi:10.1007/ s00382-011-1109-y

Gastineau G, D'Andrea F, Frankignoul C (2013) Atmospheric response to the North Atlantic ocean variability on seasonal to decadal time scales. Clim Dynam 40:2311-2330. doi:10.1007/ s00382-012-1333-0

Griffies SM, Bryan K (1997) A predictability study of simulated North Atlantic multidecadal variability. Clim Dynam 13:459-487

Hanley J, Caballero R (2012) The role of large-scale atmospheric flow and Rossby wave breaking in the evolution of extreme windstorms over Europe. Geophys Res Lett 39:L21708. doi:10.1029/ 2012GL053408

Hoskins BJ, Valdes PJ (1990) On the existence of storm-tracks. J Atmos Sci 47:1854-1864 doi:10.1175/15200469(1990)047<1854:OTEOST>2.0.CO;2

Hurrell JW, van Loon H (1997) Decadal variations in climate associated with the North Atlantic Oscillation. Clim Chang 36:301-326

Jungclaus JH, Keenlyside N, Botzet M, Haak H, Luo JJ, Latif M, Marotzke J, Mikolajewicz U, Roeckner E (2006) Ocean circulation and tropical variability in the coupled model
ECHAM5/MPI-OM. J Clim 19:3952-3972. doi:10.1175/ JCLI3828.1

Kalnay E, Kanamitsu M, Kistler R, Collins W, Deaven D, Gandin L, Iredell M, Saha S, White G, Woollen J, Zhu Y, Chelliah M, Ebisuzaki W, Higgins W, Janowiak J, Mo KC, Ropelewski C, Wang J, Leetmaa A, Reynolds R, Jenne R, Joseph D (1996) The NCEP/NCAR 40-year reanalysis project. Bull Am Meteorol Soc 77:437-471

Klawa M, Ulbrich U (2003) A model for the estimation of storm losses and the identification of severe winter storms in Germany. Nat Hazards Earth Syst Sci 3:725-732

Kushnir Y, Robinson WA, Chang P, Robertson AW (2006) The physical basis for predicting Atlantic sector seasonal-to-interannual climate variability. J Clim 19:5949-5970

Kwon YO, Alexander MA, Bond NA, Frankignoul C, Nakamura H, Qiu B, Thompson L (2010) Role of the Gulf Stream and Kuroshio-Oyashio systems in large-scale atmosphere-ocean interaction: a review. J Clim 23:3249-3281. doi:10.1175/ 2010JCLI3343.1

Latif M (1998) Dynamics of interdecadal variability in coupled ocean-atmosphere models. J Clim 11:602-624. doi:10.1175/ 1520-0442(1998)011<0602:DOIVIC >2.0.CO;2

Latif M, Roeckner E, Botzet M, Esch M, Haak H, Hagemann S, Jungclaus J, Legutke S, Marsland S, Mikolajewicz U, Mitchell J (2004) Reconstructing, monitoring, and predicting multidecadalscale changes in the North Atlantic thermohaline circulation with sea surface temperature. J Clim 7:1605-1614. doi:10.1175/15200442(2004)017<1605:RMAPMC > 2.0.CO;2

Latif M, Collins M, Pohlmann H, Keenlyside N (2006) A review of predictability studies of Atlantic sector climate on decadal time scales. J Clim 19:5971-5987

Leckebusch GC, Renggli D, Ulbrich U (2008) Development and application of an objective storm severity measure for the northeast Atlantic region. Meteor Z 17:575-587 doi:10.1127/ 0941-2948/2008/0323

Liu WT, Katsaros KB, Businger JA (1979) Bulk parameterization of air-sea exchanges of heat and water-vapor including the molecular constraints at the interface. J Atmos Sci 36:1722-1735. doi:10.1175/1520-0469(1979)036<1722: BPOASE $>2.0 . \mathrm{CO} ; 2$

Matei D, Baer J, Jungclaus JH, Haak H, Müller WA, Marotzke J (2012) Multiyear prediction of the Atlantic meridional overturning circulation. Science 335:76-79. doi:10.1126/science. 1210299

McCabe GJ, Palecki MA, Betancourt JL (2004) Pacific and Atlantic Ocean influences on multidecadal drought frequency in the United States. Proc Natl Acad Sci USA 101:4136-4141. doi:10. 1073/pnas.0306738101

Meehl GA, Goddard L, Murphy J, Stouffer RJ, Boer G, Danabasoglu G, Dixon K, Giorgetta MA, Greene AM, Hawkins E, Hegerl G, Karoly D, Keenlyside N, Kimoto M, Kirtman B, Navarra A, Pulwarty R, Smith D, Stammer D, Stockdale T (2009) Decadal prediction can it be skillful?. Bull Am Meteorol Soc 90:1467-1485

Nakamura H, Sampe T, Goto A, Ohfuchi W, Xie SP (2008) On the importance of midlatitude oceanic frontal zones for the mean state and dominant variability in the tropospheric circulation. Geophys Res Lett 35. doi:10.1029/2008GL034010

Pinto JG, Zacharias S, Fink AH, Leckebusch GC, Ulbrich U (2009) Factors contributing to the development of extreme North Atlantic cyclones and their relationship with the NAO. Clim Dynam 32:711-737. doi:10.1007/s00382-008-0396-4

Plackett RL (1983) Karl Pearson and the chi-squared test. Int Stat Rev. 51:59-72. doi:10.2307/1402731

Pohlmann H, Smith DM, Balmaseda MA, Keenlyside NS, Masina S, Matei D, Müller WA, Rogel P, da Costa ED (2013) 
Predictability of the mid-latitude Atlantic meridional overturning circulation in a multi-model system. Clim Dynam 41:775-785. doi:10.1007/s00382-013-1663-6

Renggli D (2011) Seasonal predictability of wintertime climate over the North Atlantic and Europe. Dissertation, Freie Universität Berlin. http://www.diss.fu-berlin.de

Rodwell MJ, Rowell DP, Folland CK (1999) Oceanic forcing of the wintertime North Atlantic Oscillation and European climate. Nature 398:320-323. doi:10.1038/18648

Roeckner E, Brokopf R, Esch M, Giorgetta M, Hagemann S, Kornblueh L, Manzini E, Schlese U, Schulzweida U (2006) Sensitivity of simulated climate to horizontal and vertical resolution in the ECHAM5 atmosphere model. J Clim 19:3771-3791. doi:10.1175/JCLI3824.1

Schreiber T, Schmitz A (2000) Surrogate time series. Physica D 142:346-382

Smith TM, Reynolds R, Peterson TC, Lawrimore J (2007) Improvements to NOAA's historical merged land-ocean surface temperature analysis (1880-2006). J Clim 16:1601-1612

Sutton RT, Hodson DLR (2003) Influence of the ocean on North Atlantic climate variability 1871-1999. J Clim 16:3296-3313

Torrance C, Compo GP (1998) A practical guide to wavelet analysis. Bull Am Meteorol Soc 79:61-78

Ulbrich U, Fink AH, Klawa M, Pinto JG (2001) Three extreme storms over Europe in December 1999. Weather 56:70-80
Ulbrich U, Pinto JG, Kupfer H, Leckebusch GC, Spangehl T, Reyers M (2008) Changing Northern Hemisphere storm tracks in an ensemble of IPCC climate change simulations. J Clim 21:1669-1679. doi:10.1175/2007JCLI1992.1

Wang XL, Zwiers FW, Swail VR, Feng Y (2009) Trends and variability of storminess in the northeast Atlantic region, 1874-2007. Clim Dynam 33:1179-1195. doi:10.1007/s00382008-0504-5

Wilson C, Sinha B, Williams RG (2009) The effect of ocean dynamics and orography on atmospheric storm tracks. J Clim 22:3689-3702. doi:10.1175/2009JCLI2651.1

Woollings T, Gregory JM, Reyers M, Pinto JG, Brayshaw DJ (2012) Ocean-atmosphere interaction in the Atlantic storm track response to climate change. Nat Geosci 5:313-317. doi:10. 1038/ngeo1438

Yoshimori M, Raible C, Stocker TF, Renold M (2009) Simulated decadal oscillations of the Atlantic meridional overturning circulation in a cold climate. Clim Dynam 34:101-121. doi:10. 1007/s00382-009-0540-9

Yu L, Weller RA (2007) Objectively analyzed air-sea heat fluxes for the global ice-free oceans (1981-2005). Bull Am Meteorol Soc:527-539. doi:10.1175/BAMS-88-4-527

Zhu X, Jungclaus J (2008) Interdecadal variability of the meridional overturning circulation as an ocean internal mode. Clim Dynam 31:731-741. doi:10.1007/s00382-008-0383-9 